\title{
Gestational Weight Gain and Overweight in Children Aged 3-6 Years
}

\author{
Lianhong Guo ${ }^{1,2,3}$, Jufen $\mathrm{Liu}^{2}$, Rongwei Ye ${ }^{2}$, Jianmeng $\mathrm{Liu}^{2}$, Zhixiong Zhuang ${ }^{1,4}$, and Aiguo Ren² \\ ${ }^{1}$ Department of Health Toxicology, School of Public Health, Central South University, Changsha, Hunan, China \\ ${ }^{2}$ Institute of Reproductive and Child Health/Ministry of Health Key Laboratory of Reproductive Health, School of Public Health, \\ Peking University, Beijing, China \\ ${ }^{3}$ College of Science, Northwest A\&F University, Yangling, Shaanxi, China \\ ${ }^{4}$ Center for Disease Control and Prevention, Shenzhen, Guangdong, China
}

Received September 7, 2014; accepted February 10, 2015; released online June 27, 2015

Copyright $(\odot 2015$ Lianhong Guo et al. This is an open access article distributed under the terms of Creative Commons Attribution License, which permits unrestricted use, distribution, and reproduction in any medium, provided the original author and source are credited.

\begin{abstract}
Objective: To determine whether gestational weight gain $(\mathrm{GWG})$ was associated with increased odds of childhood overweight after accounting for pre-pregnancy BMI.

Methods: In a prospective cohort study based on a premarital and perinatal health care system in China, data of 100612 mother-child pairs were obtained. The main exposure was GWG as both a continuous and categorical variable. The outcome measure was overweight, defined by age- and sex-specific cutoff values for body mass index (BMI) in children aged 3-6 years.

Results: A 1-kg increase in maternal GWG was associated with an increase of 0.009 ( $95 \%$ confidence interval [CI]: $0.007-0.010, P<0.001)$ in children's mean BMI; in the subgroup of pre-pregnancy overweight/obese mothers, the increase in children's BMI was 0.028 (95\% CI, 0.017-0.039, $P<0.001)$. Excessive GWG played an important role in childhood overweight when adequate GWG was used as the reference, with an odds ratio (OR) of 1.21 (95\% CI, 1.12-1.29). The risk was highest (OR 2.22; 95\% CI, 1.79-2.76) in the children of mothers who were overweight/ obese before pregnancy and gained excessive weight during pregnancy.

Conclusions: Greater maternal GWG was associated with greater offspring BMI, and the risk of overweight was doubled in children whose mothers were overweight/obese before pregnancy and gained excessive weight during pregnancy. As a result, maintenance of appropriate weight gain during pregnancy and prophylaxis of maternal overweight/obesity before pregnancy should be a strategy for preventing childhood overweight/obesity.
\end{abstract}

Key words: cohort study; gestational weight gain; childhood overweight; birth weight; maternal pre-pregnancy BMI

\section{INTRODUCTION}

Childhood obesity has become a serious public health problem and has attracted much attention across all geographic areas, ethnic backgrounds, and cultures in the last three decades. ${ }^{1-7}$ Obese children are more likely to become obese adults than non-obese children. ${ }^{8,9}$ Childhood obesity is linked to both short-term and long-term health consequences, including cardiovascular events, coronary heart disease, hypertension, some types of cancer, dyslipidemia, diabetes mellitus, gallbladder disease, respiratory disease, gout, and arthritis. ${ }^{10-14}$ Genetic, environmental, and lifestyle factors account for most of the overweight prevalence in children; these include parental obesity, gestational age, birth order, socioeconomic status, residence in a singleparent household, watching large amounts of television, and lack of physical activity. ${ }^{15-22}$

In China, rapid economic growth, lack of physical activity, and the replacement of a traditional Chinese diet with a "Western diet" have led to a serious obesity problem. A systematic review showed that there is an increasing trend in the prevalence of obesity in preschool children, from $0.7 \%$ in $1986-1990$ to $6.8 \%$ in $2006-2010 .^{3}$ In the meantime, China Health and Nutrition Survey data have indicated that weight status in adults is also troublesome. There were increases of $1.2 \mathrm{~kg} / \mathrm{m}^{2}$ in BMI, $67.0 \%$ in the prevalence of overweight, and $168.0 \%$ in the prevalence of obesity between 1993 and $2009 .{ }^{23}$ Therefore, we need to take effective actions to curb this trend. 
Gestation is a crucial period of time during which both mothers and children grow, develop, and undergo physiological changes. Many studies have shown that childhood obesity has roots in overnutrition during fetal development. ${ }^{24,25}$ Several studies have suggested that there is an association between gestational weight gain (GWG) and downstream weight status in childhood and throughout adulthood. ${ }^{6,26-29}$ However, the existing evidence does not allow inferences to be drawn; sample sizes and age groups vary markedly among studies, which may influence the precision of the estimates. Moreover, different reference groups, Institute of Medicine guidelines on maternal GWG, and cutoff values have been used in different studies. Furthermore, it is not clear whether the association between maternal GWG and childhood overweight is linear or nonlinear. We hypothesized that maternal GWG would have a linear relationship with offspring's risk of overweight. Indeed, Oken found that gestational weight gain was linearly associated with adolescent adiposity in the Growing Up Today Study. ${ }^{30}$ However, other studies have reported a U- or Jshaped association where greater overweight risks were found in the lowest and highest maternal gains in U-shaped association, while normal maternal gain had less risk of offspring overweight than inadequate maternal gain, and excessive maternal gain has the highest risk of offspring overweight in J-shaped association. ${ }^{31,32}$

We used a prospective cohort consisting of 100612 motherchild pairs to examine the association between maternal GWG and overweight in children aged 3-6 years from 16 counties or cities in China, which has been the second largest population of overweight people after the United States according to the latest statistics released by the CASS.

\section{METHODS}

\section{Study population and data sources}

We used data from a population-based premarital and perinatal health care system that was universally implemented in 16 counties or cities in two southern China provinces (Zhejiang and Jiangsu provinces). Women who entered the premarital health assessment program between December 1992 and February 1996 were enrolled before they got married, and they were followed until 42 days postpartum. Information on demographic and relevant obstetric and pregnancy outcomes, such as maternal age, education, occupation, gravidity, and weeks of gestation were collected at the time of entry, subsequent prenatal visits, or delivery. When a child was born, information on sex, birth length, and birth weight were collected. These children were born between October 1993 and December 1996. We followed the children from birth until between March and July 2000. The mean (standard deviation [SD]) follow-up between the date of birth and the date of child follow-up examination was 4.4 (3.8) years. Child's age (in months) was calculated by the date of follow-up examination minus the date of birth. At the follow-up examination, we measured each child's weight $(\mathrm{kg})$ and height $(\mathrm{cm})$, with the subjects wearing light indoor clothing without shoes or hats. Calibration of all instruments and quality control of the measurements were performed by local experts. All work was completed by trained local health care workers using a standard protocol.

The initial sample included 114161 mother-child pairs. After exclusion of 13549 pairs, as shown in Figure, we obtained a final cohort with 100612 (88.1\%) mother-child pairs. The Peking University Institutional Review Board approved this study.

\section{Explanatory variables}

The exposure to be examined was GWG as both a continuous and categorical variable. Total GWG was calculated as the difference between the weight at delivery and pre-pregnancy weight (weight at the premarital medical examination). Weight at the premarital medical examination and delivery were measured by trained health professionals. GWG was classified as inadequate, adequate, or excessive according to the IOM guidelines on GWG, which were revised in 2009 and are suitable for Chinese people. ${ }^{33,34}$ We combined overweight and obese mothers because the number of obese mothers was very small. Pre-pregnancy BMI $\left(\mathrm{kg} / \mathrm{m}^{2}\right)$ was calculated with maternal weight and height values obtained from the premarital examination, and we defined women as underweight (BMI <18.5), normal weight (BMI 18.5-24.9), and overweight/obese (BMI $\geq 25.0$ ) according to the current World Health Organization BMI cut-off points. ${ }^{35,36}$ Childhood overweight was defined according to international criteria on age- and sex-specific cutoff values for BMI. ${ }^{37}$ Specifically, cutoffs of 17.89, 17.69, 17.55, 17.47, 17.42, 17.45, and 17.55 were adopted for boys at ages 3 (33-38 months), 3.5 (39-44 months), 4 (45-50 months), 4.5 (51-56 months), 5 (57-62 months), 5.5 (63-68 months), and 6 (69-74 months) years, respectively. Respective cutoffs were 17.56, 17.40, 17.28, $17.19,17.15,17.20$, and 17.34 for girls at ages $3,3.5,4,4.5$, $5,5.5$, and 6 years.

\section{Statistical analyses}

We used chi-square test to compare characteristics of the mothers and children aged 3-6 according to maternal GWG and the association between covariates and children's overweight. We used linear regression to examine the association of GWG (as a continuous variable) with children's BMI and binary logistic regression to examine the relationship of GWG (as a categorical variable) with the risk of childhood overweight. Included covariates were child sex, age, and birth weight, as well as maternal age, education, occupation, gravidity, weeks of gestation, and year of registry. Odds ratios (ORs) and their corresponding 95\% confidence intervals (CIs) for childhood overweight were calculated from logistic regression models, with adjustment for the potential 


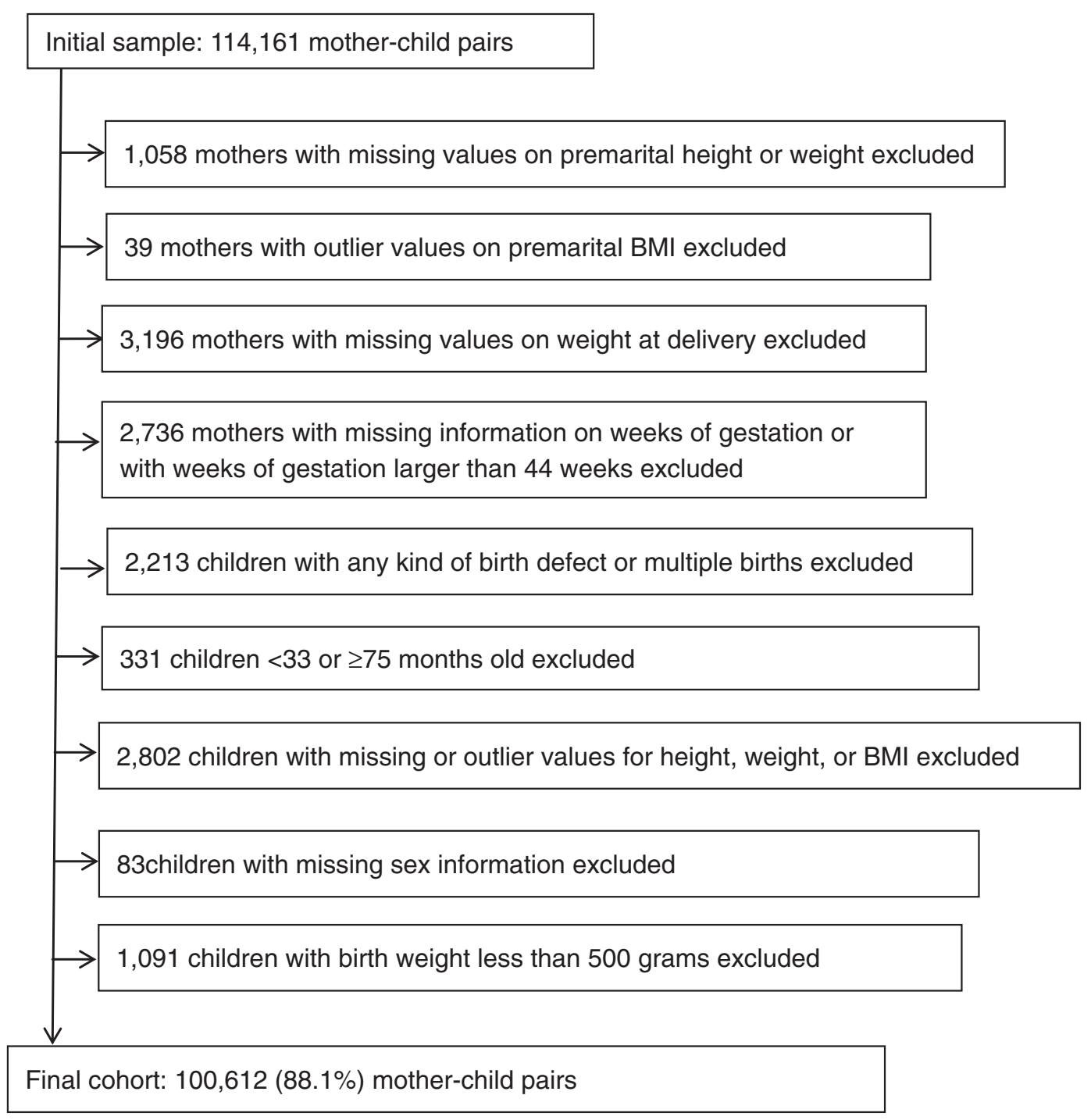

Figure. Flow chart of study selection.

confounders. We performed all analyses using SPSS version 19.0 (SPSS Inc., Chicago, IL, USA). A two-sided $P$-value $<0.05$ was considered statistically significant.

\section{RESULTS}

The anthropometric data for mothers and children and the proportion of subjects in each GWG category are shown in Table 1. Upon entering pregnancy, $81.2 \%$ of the 100612 mothers were of normal weight, $16.5 \%$ were underweight, and $2.3 \%$ were overweight/obese. $63.7 \%$ mothers had finished junior high school education and $11.5 \%$ had finished high school or college, more than half $(53.4 \%)$ were farmers, $54.9 \%$ were primigravidas, and $95.4 \%$ were nulliparous. About $51.6 \%$ of the children were boys, $7.2 \%$ were born preterm, and $1.9 \%$ were born at a low birth weight. Mean (SD) maternal age was 23.9 (2.1) years, mean (SD) pre-pregnancy BMI was $20.3(2.0) \mathrm{kg} / \mathrm{m}^{2}$, and mean (SD) total GWG was $11.7(5.0) \mathrm{kg}$. Inadequate $\mathrm{GWG}$ was present in $50.6 \%$ of the mothers, $34.9 \%$ showed adequate GWG, and $14.5 \%$ showed excessive GWG according to the IOM criteria. About $54.3 \%$ of farmer mothers gained inadequate weight during pregnancy, which was significantly higher than mothers who were factory workers or worked other jobs. The proportion of mothers who gained inadequate weight was also higher in the elementary or no education group than in the junior high school group and high school or college group. Further, the proportion of mothers who gained excessive weight was higher in the higher pre-pregnancy BMI group than in normal and underweight pre-pregnancy groups. The proportion of mothers with excessive GWG was highest in the child age group 33-44 months and lowest in child age group 69-74 months.

As shown in Table 2, the prevalence of overweight was higher in children of pre-pregnancy overweight/obese mothers than in those of normal-weight and underweight mothers. Mothers with excessive GWG had a higher rate of overweight children than mothers with adequate or inadequate GWG. The 
Table 1. Characteristics of the mothers and children aged 3-6 years according to maternal GWG in 16 Chinese counties or cities

\begin{tabular}{|c|c|c|c|c|c|}
\hline \multirow{2}{*}{ Characteristic } & \multirow{2}{*}{$\begin{array}{c}n(\%) \text { or } \\
\text { mean (SD) }\end{array}$} & \multicolumn{3}{|c|}{ GWG category $(\%) /$ mean (SD) } & \multirow{2}{*}{$P$-value } \\
\hline & & Inadequate & Adequate & Excessive & \\
\hline Number of subjects & $100612(100)$ & 50.6 & 34.9 & 14.5 & \\
\hline Maternal age, years & $23.9(2.1)$ & $23.9(2.0)$ & $24.0(2.1)$ & $24.0(2.1)$ & 0.051 \\
\hline Gestational weight gain, $\mathrm{kg}$ & $11.7(5.0)$ & $7.9(2.6)$ & $13.8(1.7)$ & $19.7(3.9)$ & $<0.001$ \\
\hline Pre-pregnancy BMI, $\mathrm{kg} / \mathrm{m}^{2}$ & $20.3(2.0)$ & $20.6(2.0)$ & $20.0(2.0)$ & $20.1(2.2)$ & $<0.001$ \\
\hline Pre-pregnancy BMl, kg/m² & & & & & $<0.001$ \\
\hline$<18.5$ & $16604(16.5)$ & 43.2 & 43.3 & 13.5 & \\
\hline $18.5-24.9$ & $81725(81.2)$ & 52.4 & 33.2 & 14.4 & \\
\hline$\geq 25.0$ & $2292(2.3)$ & 38.0 & 33.6 & 28.4 & \\
\hline Highest education & & & & & $<0.001$ \\
\hline High school or college & $11518(11.5)$ & 40.4 & 39.8 & 19.8 & \\
\hline Junior high school & $63898(63.7)$ & 50.4 & 35.0 & 14.6 & \\
\hline Elementary or none & $24952(24.8)$ & 55.7 & 32.2 & 12.1 & \\
\hline Occupation & & & & & $<0.001$ \\
\hline Farmer & $53645(53.4)$ & 54.3 & 33.1 & 12.6 & \\
\hline Factory worker & $41509(41.3)$ & 47.5 & 36.4 & 16.0 & \\
\hline Other & $5336(5.3)$ & 37.2 & 40.6 & 22.2 & \\
\hline Gravidity & & & & & $<0.001$ \\
\hline First pregnancy & $55201(54.9)$ & 53.7 & 33.0 & 13.3 & \\
\hline Second or later pregnancy & $45367(45.1)$ & 46.8 & 37.1 & 16.1 & \\
\hline Parity & & & & & $<0.001$ \\
\hline First delivery & $95976(95.4)$ & 50.5 & 34.9 & 14.6 & \\
\hline Second or later delivery & $4601(4.6)$ & 53.6 & 33.7 & 12.7 & \\
\hline Gestation, weeks & & & & & $<0.001$ \\
\hline$<37$ & $7131(7.2)$ & 62.8 & 27.3 & 9.9 & \\
\hline$\geq 37$ & $92570(92.8)$ & 49.7 & 35.4 & 14.9 & \\
\hline Child birth weight, grams & & & & & $<0.001$ \\
\hline$<2500$ & $1922(1.9)$ & 73.9 & 21.1 & 5.0 & \\
\hline$\geq 2500$ & $98690(98.1)$ & 50.1 & 35.1 & 14.8 & \\
\hline Child sex & & & & & $<0.001$ \\
\hline Female & $48728(48.4)$ & 51.4 & 34.7 & 13.9 & \\
\hline Male & $51884(51.6)$ & 49.8 & 35.1 & 15.1 & \\
\hline Child age groups, months & & & & & $<0.001$ \\
\hline $33-44$ & $16319(16.2)$ & 43.7 & 38.2 & 18.1 & \\
\hline $45-56$ & $48605(48.3)$ & 47.6 & 36.7 & 15.7 & \\
\hline $57-68$ & 34901 (34.7) & 57.4 & 31.1 & 11.4 & \\
\hline $69-74$ & $787(0.8)$ & 71.8 & 21.1 & 7.1 & \\
\hline
\end{tabular}

BMI, body mass index; GWG, gestational weight gain; SD, standard deviation.

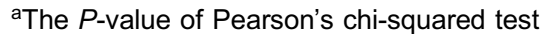

prevalence of overweight was higher in children of second or later pregnancy mothers than in those of first pregnancy mothers. Girls had a higher proportion of overweight than boys. Prevalence of overweight was greater among children with normal birth than children with inadequate birth weight. The prevalence of overweight among children was also higher in the younger child age group than in older groups, and it increased with year of registry.

In order to determine whether childhood obesity was linearly or non-linearly related to GWG, we divided GWG into 6 groups $(<5.0,5.0-9.9,10.0-14.9,15.0-19.9,20.0-$ 24.9 , and $\geq 25 \mathrm{~kg}$ ) and calculated the children's mean BMI of each group. We found children's mean BMI (15.41, 15.49, $15.58,15.65,15.73$, and 15.83) increased in the 6 GWG groups, from least to most weight gained groups. In the linear regression model without adjustment, GWG was associated with an increase in children's mean BMI, both in all mothers and in the three maternal pre-pregnancy BMI subgroups (Table 3). These associations remained after adjustment for child sex, age, and birth weight, as well as maternal age, education, occupation, gravidity, weeks of gestation, and year of registry. For example, a 1-kg increase in the GWG of all
Table 2. Association between covariates and children's overweight in 16 counties or cities in China

\begin{tabular}{|c|c|c|c|}
\hline \multirow{2}{*}{ Characteristic } & \multicolumn{2}{|c|}{ Children $n(\%)$} & \multirow{2}{*}{$P$-value ${ }^{\mathrm{a}}$} \\
\hline & Normal & Overweight & \\
\hline Maternal age, years & & & 0.372 \\
\hline $15-20$ & 7387 (92.3) & $605(7.7)$ & \\
\hline $21-24$ & $71121(93.0)$ & $5483(7.0)$ & \\
\hline $25-30$ & $13684(92.9)$ & $1049(7.1)$ & \\
\hline$\geq 31$ & $1236(92.8)$ & $97(7.2)$ & \\
\hline Pre-pregnancy BMI, kg/m² & & & $<0.001$ \\
\hline$<18.5$ & $15700(94.6)$ & $912(5.4)$ & \\
\hline $18.5-24.9$ & 75755 (92.7) & $6054(7.3)$ & \\
\hline$\geq 25.0$ & $2017(88.0)$ & $275(12.0)$ & \\
\hline GWG & & & $<0.001$ \\
\hline Inadequate & $47634(93.6)$ & $3257(6.4)$ & \\
\hline Adequate & 32519 (92.7) & $2574(7.3)$ & \\
\hline Excessive & 13319 (91.1) & $1309(8.9)$ & \\
\hline Gravidity & & & $<0.001$ \\
\hline First pregnancy & $51424(93.2)$ & $3777(6.8)$ & \\
\hline Second or later pregnancy & 42005 (92.6) & $3362(7.4)$ & \\
\hline Parity & & & 0.319 \\
\hline First delivery & $89152(92.9)$ & $6824(7.1)$ & \\
\hline Second or later delivery & $4286(93.2)$ & $315(6.8)$ & \\
\hline Gestation, weeks & & & 0.653 \\
\hline$<37$ & 6642 (93.1) & $495(6.9)$ & \\
\hline$\geq 37$ & $85993(92.8)$ & $6577(7.1)$ & \\
\hline Child birth weight, grams & & & 0.002 \\
\hline$<2500$ & $1823(94.8)$ & $99(5.2)$ & \\
\hline$\geq 2500$ & 91649 (92.9) & $7041(7.1)$ & \\
\hline Child sex & & & 0.004 \\
\hline Female & $45113(92.6)$ & $3615(7.4)$ & \\
\hline Male & $48359(93.2)$ & $3525(6.8)$ & \\
\hline Child age groups, months & & & $<0.001$ \\
\hline $33-44$ & $14901(91.3)$ & $1418(8.7)$ & \\
\hline $45-56$ & $44900(92.4)$ & $3705(7.6)$ & \\
\hline $57-68$ & $32912(94.3)$ & $1989(5.7)$ & \\
\hline $69-74$ & $759(96.4)$ & $28(3.6)$ & \\
\hline Year of registry & & & $<0.001$ \\
\hline 1993 & $62(96.9)$ & $2(3.1)$ & \\
\hline 1994 & 23191 (94.7) & $1290(5.3)$ & \\
\hline 1995 & $44471(93.2)$ & $3259(6.8)$ & \\
\hline 1996 & 25748 (90.9) & $2589(9.1)$ & \\
\hline
\end{tabular}

BMI, body mass index; GWG, gestational weight gain.

aThe $P$-value of Pearson's chi-squared test.

Table 3. Linear regression estimates for the association of maternal GWG with children's BMI at age 3-6 years according to the pre-pregnancy BMI category

\begin{tabular}{lcc}
\hline Pre-pregnancy BMI groups & $\begin{array}{c}\text { Unadjusted coefficient } \\
(95 \% \mathrm{Cl})\end{array}$ & $\begin{array}{c}\text { Adjusted }{ }^{\mathrm{a}} \text { coefficient } \\
(95 \% \mathrm{Cl})\end{array}$ \\
\hline All mothers & $0.009(0.007,0.010)$ & $0.017(0.015,0.018)$ \\
Underweight mothers & $0.014(0.010,0.018)$ & $0.022(0.018,0.026)$ \\
Normal weight mothers & $0.011(0.009,0.013)$ & $0.019(0.017,0.021)$ \\
Overweight/Obese mothers & $0.028(0.017,0.039)$ & $0.034(0.023,0.045)$ \\
\hline
\end{tabular}

$\mathrm{BMI}$, body mass index; $\mathrm{Cl}$, confidence interval; GWG, gestational weight gain.

${ }^{a}$ Adjusted for child sex, age, child birth weight, maternal age, education, occupation, gravidity, weeks of gestation, and year of registry.

mothers resulted in a mean increase of 0.009 BMI units in their offspring. Moreover, in the subgroup of overweight/ obese mothers, $1 \mathrm{~kg}$ of GWG accounted for an average increase in children's BMI of 0.028 . 
Table 4. Binary logistic regression estimates for the association of maternal GWG with children's overweight at age 3-6 years stratified by maternal pre-pregnancy BMla

\begin{tabular}{lcccc}
\hline \multirow{2}{*}{$\begin{array}{l}\text { Pre-pregnancy } \\
\text { BMI }\end{array}$} & \multicolumn{3}{c}{ OWG categories, } & \multirow{2}{*}{ Total } \\
\cline { 2 - 4 } & Inadequate & Adequate & Excessive & \\
\hline BMI < 18.5 & 0.62 & 0.69 & 0.93 & 0.71 \\
& $(0.55,0.70)$ & $(0.61,0.76)$ & $(0.79,1.10)$ & $(0.66,0.77)$ \\
BMI 18.5-24.9 & 0.91 & 1.00 & 1.13 & 1.00 \\
& $(0.85,0.96)$ & & $(1.04,1.22)$ & \\
BMI $\geq 25.0$ & 1.18 & 1.78 & 2.22 & 1.73 \\
& $(0.92,1.50)$ & $(1.43,2.22)$ & $(1.79,2.76)$ & $(1.52,1.97)$ \\
Total & 0.91 & 1.00 & 1.21 & \\
& $(0.86,0.97)$ & & $(1.12,1.29)$ \\
\hline
\end{tabular}

$\mathrm{BMI}$, body mass index; $\mathrm{Cl}$, confidence interval; GWG, gestational weight gain; OR, odds ratio.

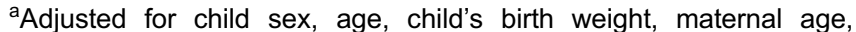
education, occupation, gravidity, weeks of gestation, and year of registry.

Table 4 shows the relative risks of childhood overweight stratified by maternal pre-pregnancy BMI and GWG. After adjustment for all confounding factors mentioned above, the odds of childhood overweight were significantly higher in children born to mothers with pre-pregnancy overweight/ obesity than in those born to mothers with normal weight. Excessive GWG was associated with an overall increase of $21 \%$ in the odds of childhood overweight compared with adequate GWG. In addition, we analyzed the risk of childhood overweight according to nine joint groups of maternal prepregnancy BMI and GWG. Children born to mothers with both pre-pregnancy normal weight and adequate GWG were used as the reference group. Excessive GWG was associated with an increased risk of offspring overweight in normal weight and overweight/obese mothers. Meanwhile, adequate GWG was also associated with an increased risk of childhood overweight in overweight/obese mothers. These results suggest that adequate GWG may also be associated with increased risk of childhood overweight in the overweight/ obese group. Of further note, children of mothers who were overweight/obese before pregnancy and displayed excessive GWG were $122 \%$ more likely to be overweight.

\section{DISCUSSION}

In this large prospective cohort study, we found that maternal GWG was linearly associated with the BMI of children aged 3-6 years. The odds of childhood overweight were $21 \%$ greater for the children of mothers who gained more than the weight gain recommendations than for children of mothers who met the weight gain recommendations.

Our results are consistent with several studies supporting a positive association between GWG and childhood obesity. A meta-analysis by Tie showed that, after eliminating the effect of publication bias by trim and fill analyses, the odds of excessive GWG and childhood overweight still remained statistically significant (OR 1.21;95\% CI, 1.05-1.40). ${ }^{38}$ Another prospective pregnancy cohort study conducted in the United Kingdom found that women who showed relatively higher GWG were more likely to have offspring with greater BMI, and greater pre-pregnancy weight was associated with greater offspring adiposity at the age of 9 years. ${ }^{39}$ Another multicenter, multiethnic cohort study suggested that the odds of overweight in the offspring at age 7 were $48 \%$ greater for children of mothers who gained excessive weight than for children of mothers who gained adequate weight (OR 1.48; 95\% CI, 1.06-2.06). ${ }^{40}$ These and our findings emphasize the importance of appropriate weight gain during gestation in the prevention of childhood overweight and obesity. Moreover, the risk of childhood overweight was highest in pre-pregnancy overweight/obese mothers (OR 2.22; 95\% CI, 1.79-2.76) in our study, highlighting the need to include weight counseling in preconception care.

Joint associations of maternal pre-pregnancy BMI and GWG with the risk of childhood overweight were also considered in our study, and we used children born to mothers with pre-pregnancy normal weight and also with adequate GWG as the reference. Children born to mothers with prepregnancy normal weight or overweight/obesity and also with excessive GWG had a higher risk of childhood overweight at 3-6 years old. Moreover, children born to mothers with prepregnancy overweight/obesity and also with adequate GWG also has a higher risk of childhood overweight at 3-6 years old. Our result can be seen as an extension of the relationship between GWG and infancy overweight risk. ${ }^{41}$

The pregnant women in our study had lower mean prepregnancy BMI $\left(20.3 \mathrm{~kg} / \mathrm{m}^{2}\right)$ and lower mean GWG $(11.7 \mathrm{~kg})$ than American women $\left(24.6 \mathrm{~kg} / \mathrm{m}^{2} \text { and } 15.6 \mathrm{~kg} \text {, respectively }\right)^{29}$ and German women $\left(22.6 \mathrm{~kg} / \mathrm{m}^{2}\right.$ and $14.3 \mathrm{~kg}$, respectively). ${ }^{42}$ More than half $(50.6 \%)$ of the women in our study gained inadequate weight during pregnancy and $14.5 \%$ excessive weight, while $14 \%$ of American women gained inadequate weight and $51 \%$ excessive weight, ${ }^{29}$ and $27.4 \%$ of German women gained inadequate weight and $37.0 \%$ excessive weight. ${ }^{42}$ In particular, we found that farmer mothers and mothers from the elementary or no education group were more vulnerable to inadequate weight gain during pregnancy. They were more likely to have imbalanced diets and poor knowledge of nutrition due to their relatively low-income status than women in other groups. The situation was opposite for mothers in Japan; Japanese women from higher socioeconomic backgrounds appeared to be at greater risk for inadequate weight gain. ${ }^{43}$ Slender women may be more sensitive to fashion trends, so they consciously try to keep fit even if they are pregnant. ${ }^{43}$ In addition, the children in our cohort had a much lower prevalence of overweight compared to children in Western societies, such as the United States and the European Union countries. ${ }^{5,6}$ These differences seem 
to support the notion that there is an association between maternal GWG and childhood overweight.

Across the age groups of children, the proportion of mothers in each GWG category and the proportion of children's overweight look quite different. The proportion of mothers with excessive GWG and children's overweight were higher in the younger child age group than among older groups. Aside from genetic and environmental factors, the cultural and historical belief that a fat child symbolizes prosperity of the family may have played an important role in this situation. As time passed, we speculated that this belief may have generated a trend in mothers gaining more weight during pregnancy and feeding their children more high-calorie food than mothers before. So it was not surprising that we observed this trend across child age groups.

We noticed that the higher pre-pregnancy BMI groups had higher proportions of mothers who gained excessive weight during pregnancy than lower-BMI groups. In the higher prepregnancy BMI groups, mothers may be more likely to eat higher calorie foods, do less physical activity, and use automobiles more because of life habits. In addition, these mothers may have failed to maintain their fitness before becoming pregnant. They may have continued these habits even after becoming pregnant, which could have resulted in gaining more weight during pregnancy than mothers from lower pre-pregnancy BMI groups. As maternal pregravid overweight/obesity and excessive weight gain during pregnancy are not perceived as a threat to the baby, mothers are unlikely to take measures to avoid these states. Relevant knowledge of prevention of these conditions is urgently needed among women of child-bearing age.

We also noticed that the risk of childhood overweight was highest among pre-pregnancy overweight/obese mothers. This may be due to the genetic association between parents and children. Indeed, reviews of the data on twin studies and on responses to chronic overfeeding and negative energy suggest that up to $70 \%$ of the susceptibility to gain weight may be inherited. ${ }^{44,45}$ However, children lived with their overweight/ obese mothers and therefore shared a similar environment. The fact that the higher pre-pregnancy BMI groups had higher proportions of mothers who gained excessive weight during pregnancy may make the situation worse. However, the genetic predisposition towards overweight among children of overweight/obese mothers is not modifiable. Therefore, changes to diet and physical environment are essential if we want to have an effective impact. ${ }^{46,47}$ Other potential mechanisms of childhood obesity need to be explored to curb the epidemic.

It was also interesting that $54.9 \%$ mothers were primigravid, while $95.4 \%$ mothers were primiparous. The reason may be that unplanned pregnancies are common in China and the induced abortion rate is high due to the onechild policy. On the one hand, many families chose to abide by the one-child policy because the parents believed that they should "give birth to fewer children, but give them better care and education", though the policy allows locally interpreted variations regarding having two or more children. ${ }^{48}$ On the other hand, the abortion rate of unmarried women in some cities has been found to be higher than that of married women. ${ }^{49}$ As a result, induced abortion is a common practice among women who seek to limit the number of children and to terminate unplanned pregnancies. In the whole nation, the ratio of the national abortion rate to normal birth rate is 0.6 , according to the director of the Center for Clinical Research and Training at the Shanghai Institute of Planned Parenthood. Against this background, each household has fewer children, who have more chance to be overfed and become overweight in the long run. ${ }^{50}$

Because GWG is a modifiable factor that can be controlled when adequate prenatal nutritional counseling is provided, and because trimester-specific GWG can predict the likelihood of overweight of children, it should be possible to identify women at risk of inappropriate GWG as early as the second trimester. ${ }^{51}$ Monitoring weight gain throughout pregnancy, especially the early weeks of gestation, would help to improve the health outcomes of children, although the majority of health care counseling on GWG and nutrition is given to obese patients. ${ }^{52-54} \mathrm{~A}$ review by Guelinckx et al showed that only two out of seven intervention trials focusing on GWG, nutrition, and physical activity achieved a significant decrease in GWG. ${ }^{55}$ This means that we need to formulate effective strategies to help overweight and obese pregnant women live a healthy life and gain an appropriate amount of weight during pregnancy.

The current study was prospective in design, and the exposure variable was collected before outcomes were known. This helps to minimize the recall bias that is often present in retrospective studies, in which women may provide wrong values for weeks of gestation, child birth weight, and maternal weight and height due to deficiencies in memory. For example, in our study, birth weight was an important confounding factor. Because the follow-up date had been several years from the date of child birth, the mother could probably only remember the approximate value (eg, $3000 \mathrm{~g}$ ) instead of an accurate value (eg, $2960 \mathrm{~g}$ ). In addition, the present study included a large sample, which enabled us to conduct stratified analyses by maternal pre-pregnancy BMI, which strengthened the findings of our study. Furthermore, the cohort data were obtained in a standardized manner by health care professionals rather than self-reported. There are two limitations in our study that warrant mention. One limitation is that the pre-pregnancy BMI was calculated by the premarital weight and height. However, since about $86 \%$ women got pregnant within a year (mean [SD], 5.5[6.2] months) after the premarital assessment, we believe that the weight of mothers did not change significantly from the time of the premarital assessment to the time of conception, since the premarital assessment is conducted immediately before 
marriage in China. Another limitation was that information on breastfeeding, childhood nutrition, and physical activity was not collected in this study. Because our sample was mainly from counties or cities where lifestyle factors may not be significantly different, the impact, if any, is expected to be small. Future studies should consider the effects of these factors.

\section{Conclusion}

Greater maternal GWG was associated with greater BMI of children at the age of 3-6 years, and the risk of childhood overweight was the highest for children of mothers who were overweight/obese before pregnancy and gained excessive weight during gestation. These findings indicate that childhood obesity prevention should be a component of preconceptional and prenatal care, which means that both the maternal pre-pregnancy BMI and GWG should be adjusted to appropriate values.

\section{ACKNOWLEDGEMENT}

Conflicts of interest: None declared.

\section{REFERENCES}

1. Thibault H, Carriere C, Langevin C, Kossi Déti E, BarbergerGateau P, Maurice S. Prevalence and factors associated with overweight and obesity in French primary-school children. Public Health Nutr. 2013;16:193-201.

2. Thow AM, Jan S, Leeder S, Swinburn B. The effect of fiscal policy on diet, obesity and chronic disease: a systematic review. Bull World Health Organ. 2010;88:609-14.

3. Yu Z, Han S, Chu J, Xu Z, Zhu C, Guo X. Trends in overweight and obesity among children and adolescents in China from 1981 to 2010: a meta-analysis. PLoS One. 2012;7:e51949.

4. Speiser PW, Rudolf MC, Anhalt H, Camacho-Hubner C, Chiarelli F, Eliakim A, et al. Childhood obesity. J Clin Endocrinol Metab. 2005;90:1871-87.

5. Ogden CL, Carroll MD, Kit BK, Flegal KM. Prevalence of obesity and trends in body mass index among US children and adolescents, 1999-2010. JAMA. 2012;307:483-90.

6. Cattaneo A, Monasta L, Stamatakis E, Lioret S, Castetbon K, Frenken F, et al. Overweight and obesity in infants and preschool children in the European Union: a review of existing data. Obes Rev. 2010;11:389-98.

7. Deierlein AL, Siega-Riz AM, Herring AH, Adair LS, Daniels JL. Gestational weight gain and predicted changes in offspring anthropometrics between early infancy and 3 years. Pediatr Obes. 2012;7:134-42.

8. Must A. Does overweight in childhood have an impact on adult health. Nutr Rev. 2003;61:139-42.

9. Magarey AM, Daniels LA, Boulton TJ, Cockington RA. Predicting obesity in early adulthood from childhood and parental obesity. Int J Obes Relat Metab Disord. 2003;27: 505-13.

10. Sabo RT, Lu Z, Daniels S, Sun SS. Serial childhood BMI and associations with adult hypertension and obesity: the Fels Longitudinal Study. Obesity (Silver Spring). 2012;20:1741-3.

11. Lloyd LJ, Langley-Evans SC, McMullen S. Childhood obesity and adult cardiovascular disease risk: a systematic review. Int J Obes (Lond). 2010;34:18-28.

12. Pi-Sunyer FX. Medical hazards of obesity. Ann Intern Med. 1993;119:655-60.

13. Shapiro LR, Crawford PB, Clark MJ, Pearson DL, Raz J, Huenemann RL. Obesity prognosis: a longitudinal study of children from the age of 6 months to 9 years. Am J Public Health. 1984;74:968-72.

14. van Grieken A, Renders CM, Wijtzes AI, Hirasing RA, Raat H. Overweight, obesity and underweight is associated with adverse psychosocial and physical health outcomes among 7-year-old children: the 'Be active, eat right' study. PLoS One. 2013;8: e67383.

15. Mamun AA, Mannan M, Doi SA. Gestational weight gain in relation to offspring obesity over the life course: a systematic review and bias-adjusted meta-analysis. Obes Rev. 2014;15: 338-47.

16. Mata J, Munsch S. Obesity in children and adolescents: Risks, causes, and therapy from a psychological perspective. Bundesgesundheitsblatt Gesundheitsforschung Gesundheitsschutz. 2011;54:548-54.

17. Dhir S, Ryan F. Measurement, causes and management of overweight and obesity in children. Community Pract. 2010;83: $32-4$.

18. Rolland-Cachera MF, Deheeger M, Maillot M, Bellisle F. Early adiposity rebound: causes and consequences for obesity in children and adults. Int J Obes (Lond). 2006;30 Suppl 4:S11-7.

19. Sugimori H, Yoshida K, Izuno T, Miyakawa M, Suka M, Sekine $\mathrm{M}$, et al. Analysis of factors that influence body mass index from ages 3 to 6 years: A study based on the Toyama cohort study. Pediatr Int. 2004;46:302-10.

20. Parsons TJ, Power C, Logan S, Summerbell CD. Childhood predictors of adult obesity: a systematic review. Int J Obes Relat Metab Disord. 1999;23 Suppl 8:S1-107.

21. Hediger ML, Overpeck MD, McGlynn A, Kuczmarski RJ, Maurer KR, Davis WW. Growth and fatness at three to six years of age of children born small- or large-for-gestational age. Pediatrics. 1999;104:e33.

22. Gillman MW, Rifas-Shiman S, Berkey CS, Field AE, Colditz GA. Maternal gestational diabetes, birth weight, and adolescent obesity. Pediatrics. 2003;111:e221-6.

23. Wang H, Zhai F. Programme and policy options for preventing obesity in China. Obes Rev. 2013;14 Suppl 2:134-40.

24. Thornton YS, Smarkola C, Kopacz SM, Ishoof SB. Perinatal outcomes in nutritionally monitored obese pregnant women: a randomized clinical trial. J Natl Med Assoc. 2009;101:569-77.

25. Adamo KB, Ferraro ZM, Brett KE. Can we modify the intrauterine environment to halt the intergenerational cycle of obesity? Int J Environ Res Public Health. 2012;9:1263-307.

26. Schack-Nielsen L, Michaelsen KF, Gamborg M, Mortensen EL, Sørensen TI. Gestational weight gain in relation to offspring body mass index and obesity from infancy through adulthood. Int J Obes (Lond). 2010;34:67-74.

27. Margerison Zilko CE, Rehkopf D, Abrams B. Association of maternal gestational weight gain with short- and long-term 
maternal and child health outcomes. Am J Obstet Gynecol. 2010;202:574.e1-8.

28. Dello Russo M, Ahrens W, De Vriendt T, Marild S, Molnar D, Moreno LA, et al. Gestational weight gain and adiposity, fat distribution, metabolic profile, and blood pressure in offspring: the IDEFICS project. Int J Obes (Lond). 2013;37:914-9.

29. Oken E, Taveras EM, Kleinman KP, Rich-Edwards JW, Gillman MW. Gestational weight gain and child adiposity at age 3 years. Am J Obstet Gynecol. 2007;196:322.e1-8.

30. Oken E, Rifas-Shiman SL, Field AE, Frazier AL, Gillman MW. Maternal gestational weight gain and offspring weight in adolescence. Obstet Gynecol. 2008;112:999-1006.

31. Keim SA, Pruitt NT. Gestational weight gain and child cognitive development. Int J Epidemiol. 2012;41:414-22.

32. Whitaker RC. Predicting preschooler obesity at birth: the role of maternal obesity in early pregnancy. Pediatrics. 2004;114: e29-36.

33. Medicine Io. In: Rasmussen KM, Yaktine AL, editors. Weight Gain During Pregnancy: Reexamining the Guidelines. The National Academies Collection: Reports funded by National Institutes of Health. Washington (DC); 2009.

34. Yang YD, Yang HX. Investigation into the clinical suitability of Institute of Medicine 2009 guidelines regarding weight gain during pregnancy for women with full term singleton fetus in China. Zhonghua Fu Chan Ke Za Zhi. 2012;47:646-50.

35. WHO Expert Consultation. Appropriate body-mass index for Asian populations and its implications for policy and intervention strategies. Lancet. 2004;363:157-63.

36. Gu D, He J, Duan X, Reynolds K, Wu X, Chen J, et al. Body weight and mortality among men and women in China. JAMA. 2006;295:776-83.

37. Cole TJ, Bellizzi MC, Flegal KM, Dietz WH. Establishing a standard definition for child overweight and obesity worldwide: international survey. BMJ. 2000;320:1240-3.

38. Tie HT, Xia YY, Zeng YS, Zhang Y, Dai CL, Guo JJ, et al. Risk of childhood overweight or obesity associated with excessive weight gain during pregnancy: a meta-analysis. Arch Gynecol Obstet. 2014;289:247-57.

39. Fraser A, Tilling K, Macdonald-Wallis C, Sattar N, Brion MJ, Benfield L, et al. Association of maternal weight gain in pregnancy with offspring obesity and metabolic and vascular traits in childhood. Circulation. 2010;121:2557-64.

40. Wrotniak BH, Shults J, Butts S, Stettler N. Gestational weight gain and risk of overweight in the offspring at age $7 \mathrm{y}$ in a multicenter, multiethnic cohort study. Am J Clin Nutr. 2008;87: 1818-24.

41. Li N, Liu E, Guo J, Pan L, Li B, Wang P, et al. Maternal prepregnancy body mass index and gestational weight gain on offspring overweight in early infancy. PLoS One. 2013;8: e77809.

42. Beyerlein A, Nehring I, Rzehak P, Heinrich J, Müller MJ, Plachta-Danielzik S, et al. Gestational weight gain and body mass index in children: results from three german cohort studies. PLoS One. 2012;7:e33205.

43. Inoue S, Naruse H, Yorifuji T, Murakoshi T, Doi H, Kawachi I. Who is at risk of inadequate weight gain during pregnancy? Analysis by occupational status among 15,020 deliveries in a regional hospital in Japan. Matern Child Health J. 2013;17: 1888-97.

44. Bouchard C, Tremblay A. Genetic influences on the response of body fat and fat distribution to positive and negative energy balances in human identical twins. J Nutr. 1997;127:943S-7S.

45. Lobstein T, Frelut ML. Prevalence of overweight among children in Europe. Obes Rev. 2003;4:195-200.

46. Wilding J. Are the causes of obesity primarily environmental? Yes.pdf. BMJ. 2012;345:e5843.

47. Frayling TM. Are the causes of obesity primarily environmental? No.pdf. BMJ. 2012;345:e5844.

48. Wang C. Induced abortion patterns and determinants among married women in China: 1979 to 2010. Reprod Health Matters. 2014;22:159-68.

49. Parry J. Chinese migrant workers are vulnerable to abortion risks, expert says. BMJ. 2011;343:d6354.

50. Yang J. China's one-child policy and overweight children in the 1990s. Soc Sci Med. 2007;64:2043-57.

51. Chmitorz A, von Kries R, Rasmussen KM, Nehring I, Ensenauer R. Do trimester-specific cutoffs predict whether women ultimately stay within the Institute of Medicine/National Research Council guidelines for gestational weight gain? Findings of a retrospective cohort study. Am J Clin Nutr. 2012;95:1432-7.

52. Ferraro ZM, Boehm KS, Gaudet LM, Adamo KB. Counseling about gestational weight gain and healthy lifestyle during pregnancy: Canadian maternity care providers' self-evaluation. Int J Womens Health. 2013;5:629-36.

53. Sui Z, Moran LJ, Dodd JM. Physical activity levels during pregnancy and gestational weight gain among women who are overweight or obese. Health Promot J Austr. 2013;24:206-13.

54. Leslie WS, Gibson A, Hankey CR. Prevention and management of excessive gestational weight gain: a survey of overweight and obese pregnant women. BMC Pregnancy Childbirth. 2013; 13:10.

55. Guelinckx I, Devlieger R, Beckers K, Vansant G. Maternal obesity: pregnancy complications, gestational weight gain and nutrition. Obes Rev. 2008;9:140-50. 